\title{
Effect of Surface Roughness on the Oxidation Behavior of a Directionally Solidified Ni-Based Superalloy at $1,100{ }^{\circ} \mathrm{C}$
}

\author{
Li Wang $\cdot$ Wei-Guo Jiang $\cdot$ Xiang-Wei Li $\cdot$ Jia-Sheng Dong $\cdot$ \\ Wei Zheng $\cdot$ Hui Feng $\cdot$ Lang-Hong Lou
}

Received: 12 August 2014/Revised: 24 September 2014/Published online: 30 January 2015

(c) The Chinese Society for Metals and Springer-Verlag Berlin Heidelberg 2015

\begin{abstract}
The effect of surface roughness on the oxidation behavior of a directionally solidified Ni-based superalloy was investigated by surface mapping microscope, scanning electron microscope and X-ray diffraction. It was found that specimens with surface roughness of $0.05 \mu \mathrm{m}$ exhibit the best oxidation resistance, while specimens with surface roughness of $0.14 \mu \mathrm{m}$ behave worse than specimens with surface roughness of $0.83 \mu \mathrm{m}$. The specimens with surface roughness of $0.05 \mu \mathrm{m}$ have the best oxidation resistance, which is mainly due to the smallest surface area exposed in air and thinnest work-hardening layer. The $\mathrm{Al}_{2} \mathrm{O}_{3}$ layer alleviates the oxidation process of the specimens with surface roughness of $0.83 \mu \mathrm{m}$, and this is the possible reason for the better oxidation resistance of samples with surface roughness of $0.83 \mu \mathrm{m}$ than samples with surface roughness of $0.14 \mu \mathrm{m}$.
\end{abstract}

KEY WORDS: Superalloy; Oxidation; Surface roughness; Surface area; Work hardening

\section{Introduction}

Directionally solidified (DS) Ni-based superalloys are widely used in gas turbine industry due to their high-temperature durability $[1,2]$. With the increases of the modern jet engines efficiency, the service temperatures and therefore the oxidation attack increases significantly [3]. Oxidation resistance is still one of the most important features for the advanced single crystal (SX) superalloys.

The high-temperature oxidation behavior of Ni-based superalloys has been studied extensively during the past decades [4-11]. Most of the works were focused on the

Available online at http://link.springer.com/journal/40195

L. Wang $(\square)$ - W.-G. Jiang · X.-W. Li · J.-S. Dong ·

W. Zheng $\cdot$ H. Feng $\cdot$ L.-H. Lou

Superalloys Division, Institute of Metal Research, Chinese

Academy of Sciences, Shenyang 110016, China

e-mail: wangli@imr.ac.cn effects of temperature [6, 9-11], atmosphere [8] and chemical compositions $[4,7]$ on oxidation behavior. There is little work concerning the effect of surface roughness on oxidation process. However, the previous studies in $\mathrm{Ni}$ alloys, $\mathrm{Fe}-\mathrm{Cr}-\mathrm{Al}$ alloys and 9-12\% $\mathrm{Cr}$ steels showed that different surface preparing process or surface roughness could result in different work-hardening layer. This will consequently accelerate the diffusion of atoms and finally lead to different oxidation behaviors [12-14]. Therefore, it is necessary to make clear whether the surface roughness will also affect the oxidation behavior of DS superalloy components.

In the present work, samples of a DS superalloy with identical chemical composition and microstructure, but different surface roughness, were prepared and exposed in air for oxidation at $1,100{ }^{\circ} \mathrm{C}$. Oxidation behaviors of samples with different surface roughness were compared. Furthermore, the surface work hardening caused by different surface preparing processes was considered in this work. Knoop hardness test of the sample surface was carried out in the present experiment to represent the workhardening layer. 


\section{Experimental}

A directionally solidified version of a third-generation $\mathrm{Ni}$ based superalloy DD33 which contains $4 \mathrm{wt} \%$ Re was used. Master alloy was initially cast in a vacuum induction melting furnace and then DS into bars with the diameter of $16 \mathrm{~mm}$ by liquid metal cooling (LMC) technique. Details of the DS process were reported in Ref. [15].

To get homogenized microstructure with cubic $\gamma^{\prime}$ phase uniformly distributed in $\gamma$ matrix, the bars were solution heat treated at $1,335{ }^{\circ} \mathrm{C}$ and then received two stages annealing at 1,150 and $870{ }^{\circ} \mathrm{C}$, respectively. Then, the plate samples with the dimension of $20 \mathrm{~mm} \times 10 \mathrm{~mm} \times 1.5 \mathrm{~mm}$ were machined from the main plane along the DS direction, as schematically shown in Fig. 1. All the samples were cut from one bar to minimize the effect of microstructure and crystal orientation. Then, some samples were grinded carefully to 600 and 1,200 grits abrasives to obtain different rough surfaces. All the samples were degreased in acetone, ultrasonically cleaned in alcohol and dried in hot air, in sequence.

Optical interferometry was performed by a surface mapping microscope (MicroXAM) to obtain 3D images to evaluate the surface roughness of samples with different finishes.

In order to characterize the work-hardening layer of samples with different surface roughness, some of the samples were cut perpendicular to the DS direction, grinded and then fine polished. Knoop hardness test (load is $0.1 \mathrm{~N}$, dwell time is $10 \mathrm{~s}$ ) was carried out every $5 \mu \mathrm{m}$ from the sample top surface, as shown schematically in Fig. 2. In order to avoid the effect of the adjacent indent, every other point was tested along the line which is $10 \mu \mathrm{m}$ away from the baseline. Three groups of parallel data were collected and averaged for each sample.

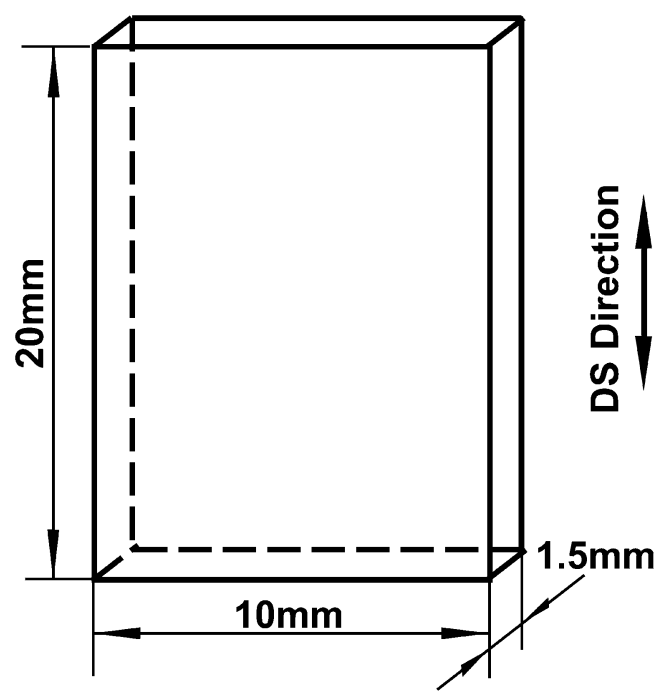

Fig. 1 Schematic diagram of the cutting of oxidation samples

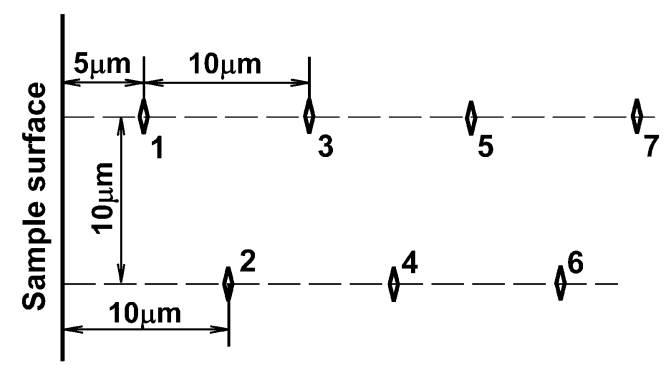

Fig. 2 Schematic illustration of the Knoop hardness test points on the sample surface

Oxidation test was performed at $1,100{ }^{\circ} \mathrm{C}$ in air in alumina crucibles for different times. After each 25 -h oxidation test, the samples were covered immediately with ceramic covers to avoid the splash of the oxidation products and cooled to room temperature. Then, they were weighted together with the alumina crucibles using an electronic balance with a resolution of $0.05 \mathrm{mg}$. Under each condition, five samples were tested and the curves of average value of mass gain versus time were plotted. In order to investigate the initial oxidation stage, some samples were exposed in air at $1,100{ }^{\circ} \mathrm{C}$ for $10,30,60$ and $300 \mathrm{~min}$, respectively.

The oxidation products were analyzed by X-ray diffraction (XRD). Both the surfaces and the cross sections of the oxide scales were observed by scanning electron microscope (SEM) equipped with energy-dispersive X-ray spectroscope (EDX).

\section{Results}

\subsection{Microstructure}

Three-dimensional surface morphologies of the samples with different surface roughnesses are shown in Fig. 3a, c, e. The surface profiles vertical to the machining direction along the lines marked in the corresponding 3D images are shown in Fig. 3b, d, f. The average surface roughnesses of the three samples were measured to be $0.83,0.14$ and $0.05 \mu \mathrm{m}$, respectively. Samples with surface roughness of $0.83 \mu \mathrm{m}$ showed very deep scratches along the machining direction (Fig. 3a). Fluctuation decreased with the decrease of surface roughness, and the maximum height differences between crests and troughs of samples with surface roughnesses of $0.83,0.14$ and $0.05 \mu \mathrm{m}$ were about $5.5,1.2$ and $0.4 \mu \mathrm{m}$, respectively (Fig. 3b, d, f).

\subsection{Hardness}

The depth profiles of Knoop hardness of the samples with different surface roughnesses are shown in Fig. 4. The Knoop hardness increased immediately from the sample 

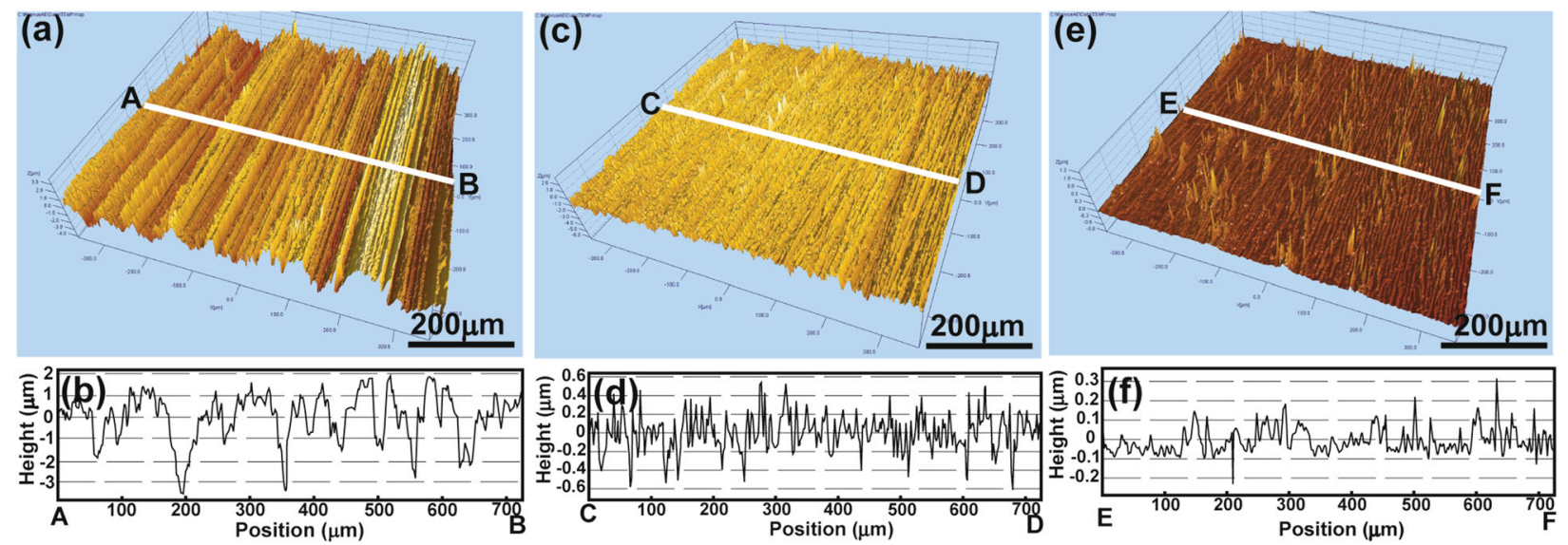

Fig. 3 Three-dimensional surface images and corresponding cross-sectional profiles of tested samples with surface roughness of $\mathbf{a}, \mathbf{b} 0.83 \mu \mathrm{m}, \mathbf{c}$, d $0.14 \mu \mathrm{m}, \mathbf{e}, \mathbf{f} 0.05 \mu \mathrm{m}$

surface and then decreased as it goes inwards. The maximum value decreased from $780 \mathrm{HK}_{0.01}$ to around 730 $\mathrm{HK}_{0.01}$ when the surface roughness decreased from 0.83 to $0.05 \mu \mathrm{m}$, and the locations of these peaks moved toward the sample surface correspondingly.

\subsection{Oxidation Products}

Figure 5 shows the curves of mass gain versus exposure time at $1,100{ }^{\circ} \mathrm{C}$ of the samples with different surface roughnesses. Different oxidation rates of different samples were obtained in different stages of oxidation, especially from 50 to $100 \mathrm{~h}$. The samples with surface roughness of $0.05 \mu \mathrm{m}$ showed the lowest mass gain, while the samples with surface roughness of $0.14 \mu \mathrm{m}$ exhibited the highest mass gain.

The XRD patterns of the samples with different surface roughnesses after oxidation at $1,100{ }^{\circ} \mathrm{C}$ for 30 and $300 \mathrm{~min}$ are illustrated in Fig. 6. After 30-min exposure, the main oxidation products were $\mathrm{NiO}, \mathrm{TaO}_{2}$ and spinel phase, as shown in Fig. 6a. It should be noted that the peaks of $\mathrm{NiO}$ and $\mathrm{TaO}_{2}$ were strengthened with the enhancement of the

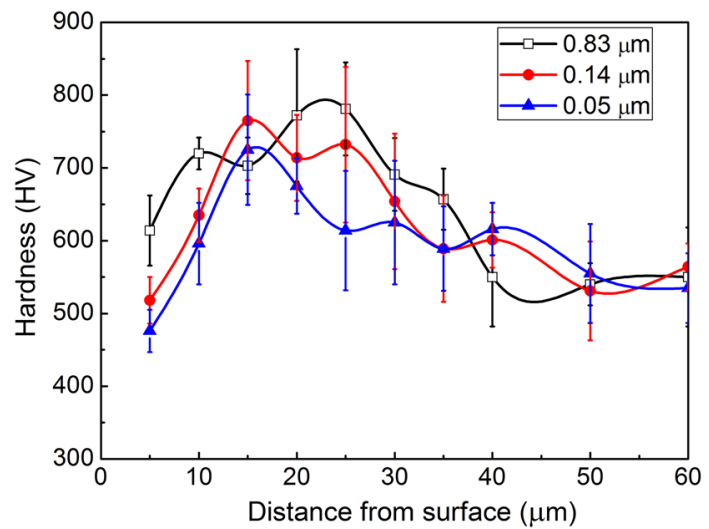

Fig. 4 Knoop hardness depth profiles of samples with different surface roughness surface quality. After oxidation at $1,100{ }^{\circ} \mathrm{C}$ for $300 \mathrm{~min}$, the complex oxidation products were formed in all those samples (Fig. 6b). Besides the oxidation products on the specimens which were exposed in $1,100{ }^{\circ} \mathrm{C}$ air for $30 \mathrm{~min}$, $\mathrm{Al}_{2} \mathrm{O}_{3}$, Ta-rich oxides $\left(\mathrm{NiTa}_{2} \mathrm{O}_{6}, \mathrm{CoTa}_{2} \mathrm{O}_{6}, \mathrm{CrTaO}_{4}\right)$ and $\mathrm{CoWO}_{4}$ were detected. The strength of $\mathrm{Al}_{2} \mathrm{O}_{3}$ peaks was similar for all the specimens, while $\mathrm{NiO}$ peaks weakened with the increase of surface roughness.

Surface oxidation morphologies of the samples oxidized for $300 \mathrm{~min}$ at $1,100{ }^{\circ} \mathrm{C}$ are presented in Fig. 7. It was shown that almost no $\mathrm{NiO}$ could be observed on the surfaces of samples with surface roughness of $0.83 \mu \mathrm{m}$. Machining scratches still could be identified. A thick layer of spinel phase was generated, and some of them spalled from the substrates (Fig. 7a). For specimens with surface roughness of $0.14 \mu \mathrm{m}$, a discontinuous $\mathrm{NiO}$ layer formed (Fig. 7b). While for specimens with surface roughness of $0.05 \mu \mathrm{m}$, as shown in Fig. $7 \mathrm{c}$ and d, a continuous layer of $\mathrm{NiO}$ was produced uniformly on the surface.

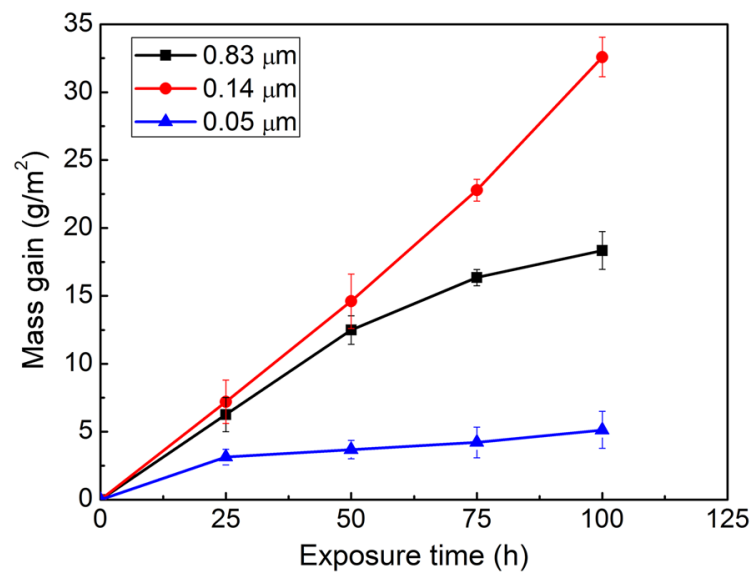

Fig. 5 Changes of mass gain versus exposure time during $1,100{ }^{\circ} \mathrm{C}$ oxidation of samples with different surface roughnesses 

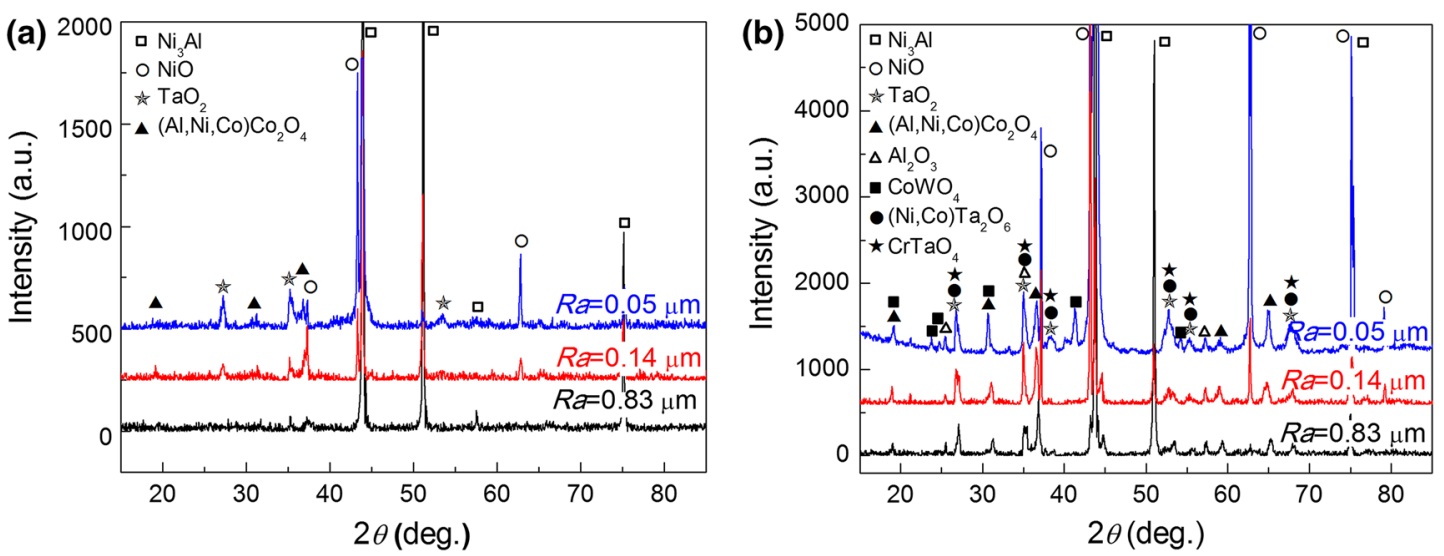

Fig. 6 XRD patterns of the samples with different surface roughnesses $(R a)$ after 30-min $\mathbf{a}, 300$-min $\mathbf{b}$ exposure at $1,100{ }^{\circ} \mathrm{C}$

Figure 8 illustrates the cross sections of oxide scales on the specimens which were oxidized in $1,100{ }^{\circ} \mathrm{C}$ for $300 \mathrm{~min}$. The oxide layer of the specimen with surface roughness of $0.83 \mu \mathrm{m}$ showed wavy geometry. According to the corresponding EDX and XRD results, a layer of spinel phase enriched in $\mathrm{Ni}$ and $\mathrm{Ta}$ was formed on the sample surface (Fig. 8a). Only small amount of $\mathrm{NiO}$ existed discontinuously

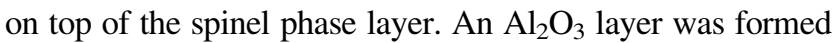
between the spinel phase layer and the substrate. For samples with surface roughnesses of 0.14 and $0.05 \mu \mathrm{m}$, as illustrated in Fig. 8b and c, three layers of oxides were generated, including an outer layer of $\mathrm{NiO}$, an intermediate continuous spinel layer containing multiple Ta-rich oxides and a continuous $\mathrm{Al}_{2} \mathrm{O}_{3}$ layer adjacent to the matrix. The oxide scale of samples with surface roughness of $0.14 \mu \mathrm{m}$ was thicker than that of samples with surface roughness of $0.05 \mu \mathrm{m}$.

\section{Discussion}

Generally, when surface conditions were concerned, three factors should be considered: surface area [16], workhardening layer [13] and the adherence of oxide scale to the sample surface [17].

First of all, surface area is a factor that affects oxidation process directly. For samples of the same apparent area, greater surface roughness always leads to a larger real surface area. The larger the real surface area exposed in air, the more the oxygen atoms diffuse into the matrix, and the faster the oxidation takes place $[12,16,18]$. Therefore, the weight gains of the samples with surface roughnesses of 0.83 and $0.14 \mu \mathrm{m}$ were much higher than that of samples with surface roughness of $0.05 \mu \mathrm{m}$ (Fig. 5). From this point, the oxidation rate should decrease in the sequence of samples with surface roughnesses of $0.83,0.14$ and $0.05 \mu \mathrm{m}$.

Secondly, it was reported that $\mathrm{Al}_{2} \mathrm{O}_{3}$ formed during oxidation at $1,100{ }^{\circ} \mathrm{C}$ in the experimental alloy [19]. The formation of the protective $\mathrm{Al}_{2} \mathrm{O}_{3}$ layer in $\mathrm{Fe}-10 \mathrm{Al}$ (at.\%) alloys was reported to be closely related to the thickness and severity of the work-hardening layer [13]. The increase of microhardness could represent the severity of work hardening [20]. For the experimental DS superalloy, the maximum value of the Knoop hardness decreased from $780 \mathrm{HK}_{0.01}$ to $730 \mathrm{HK}_{0.01}$ with the surface roughness decrease from 0.83 to $0.05 \mu \mathrm{m}$ (Fig. 4). It could be concluded that less work hardening occurred in samples with surface roughness of $0.05 \mu \mathrm{m}$. And the shift of the microhardness peaks to the sample surface indicated thinner work-hardening layer. Severer work hardening led to higher density of defects, which resulted in higher diffusion velocity of atoms through the work-hardening layer [14] and, therefore, faster selective oxidation of Al. This in turn would slowdown the following oxidation process.

At last, the adherence of the oxide scale to the sample surface is also an important factor. For specimens with
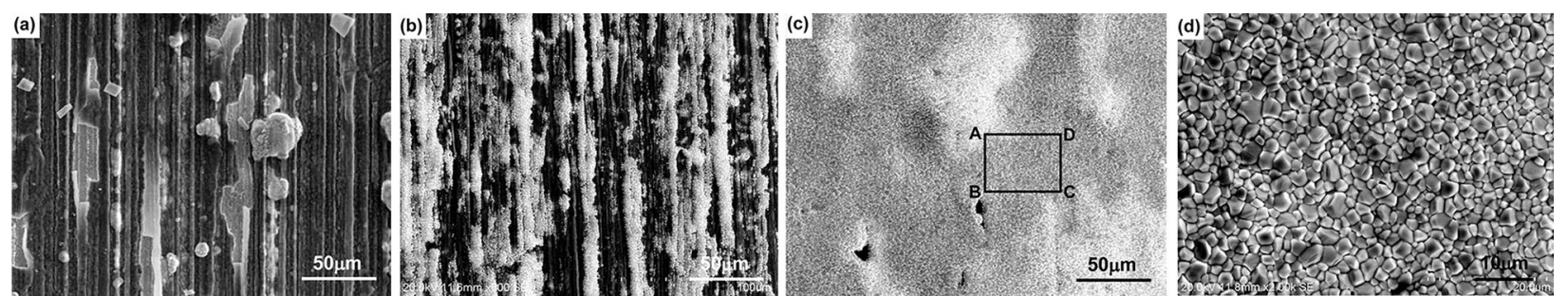

Fig. 7 Surface morphologies of samples with surface roughnesses of $0.83 \mu \mathrm{m} \mathrm{a}, 0.14 \mu \mathrm{m} \mathbf{b}, 0.05 \mu \mathrm{m} \mathbf{c}$ after exposure in air at $1,100{ }^{\circ} \mathrm{C}$ for 300 min, and high magnification view of $A B C D$ rectangle area in $\mathbf{c}, \mathbf{d}$ 

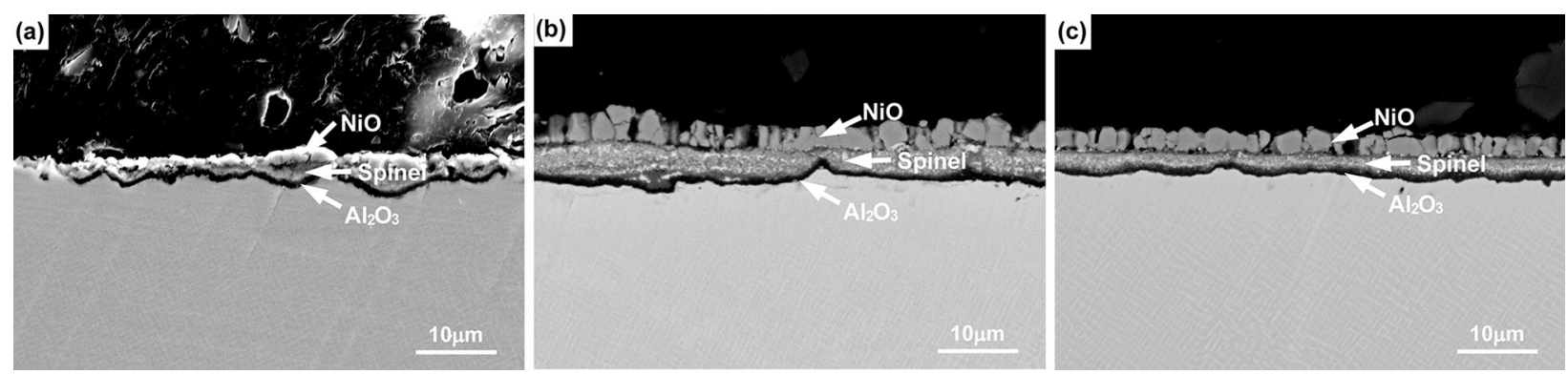

Fig. 8 The cross sections of specimens with surface roughnesses of a $0.83 \mu \mathrm{m}, \mathbf{b} 0.14 \mu \mathrm{m}, \mathbf{c} 0.05 \mu \mathrm{m}$ after $1,100{ }^{\circ} \mathrm{C}, 300$-min exposure in air

rough surface, oxidation occurs preferentially on the tips of the crests, and the oxidation products will spall easily [16]. It was also reported that the wavy geometry alters stress state in the oxide scales and, subsequently, leads to the change in stress intensity factor for cracks at the interface [20]. Finally, oxide scales are more prone to spalling from rough surfaces than those formed on smooth surfaces [21]. In the present experiment, $\mathrm{NiO}$ produced very fast at the beginning of the oxidation at $1,100{ }^{\circ} \mathrm{C}$ [19] and so did other oxidation products. However, stronger peaks of oxidation products were found on samples with surface roughness of $0.05 \mu \mathrm{m}$ but not on samples with surface roughness of $0.83 \mu \mathrm{m}$ (Fig. 6). And the thickness of oxide scales on samples with surface roughness of $0.83 \mu \mathrm{m}$ is thinner than that on samples with surface roughness of $0.05 \mu \mathrm{m}$. This was probably due to the spallation of the oxidation products during the cyclic oxidation process (Figs. 7, 8).

Above all, on the one hand, oxidation occurs faster for samples with rougher surface due to the larger surface areas and severer work-hardening layer, so does the formation of the protective $\mathrm{Al}_{2} \mathrm{O}_{3}$ layer. On the other hand, the adhesion of the oxides with the substrate was weak on a rougher surface and the oxidation products spalled easily, which indicated weakening of the protection. The combination of these effects should be responsible for the different oxidation behaviors of samples with different surface roughnesses in the present experiment.

\section{Conclusions}

(1) Different surface roughnesses result in different oxidation behaviors for the present DS nickel-based superalloy.

(2) In the present experiment, samples with surface roughness of $0.05 \mu \mathrm{m}$ show the best oxidation resistance due to the smallest surface areas exposed in air and thinner work-hardening layer.

(3) For specimens with surface roughness of $0.83 \mu \mathrm{m}$, the thick and severe work-hardening layer leads to the faster formation of $\mathrm{Al}_{2} \mathrm{O}_{3}$ layer, which alleviates the oxidation process. Probably, this is the reason for the better oxidation resistance of samples with surface roughness of $0.83 \mu \mathrm{m}$ than samples with surface roughness of $0.14 \mu \mathrm{m}$.

Acknowledgments This work was financially supported by the National Natural Science Foundation of China (No. 51201164) and National High Technology Research and Development Program of China (No. 2012AA03A511). Many thanks also go to Dr. S.M. Jiang for the helpful discussion.

\section{References}

[1] Z.Q. Hu, L.R. Liu, T. Jin, X.F. Sun, Aeroengine 31, 1 (2005)

[2] A. Karabela, L.G. Zhao, B. Lin, J. Tong, M.C. Hardy, Mater. Sci. Eng. A 567, 46 (2013)

[3] N. Czech, M. Juez-Lorenzo, V. Kolarik, W. Stamm, Surf. Coat. Technol. 108-109, 36 (1998)

[4] L. Huang, X.F. Sun, H.R. Guan, Z.Q. Hu, Surf. Technol. 200, 6863 (2006)

[5] K. Kawagishi, H. Harada, A. Sato, T. Kobayashi, J. Met. 58, 43 (2006)

[6] F.J. Liu, M.C. Zhang, J.X. Dong, Y.W. Zhang, Acta Metall. Sin. (Engl. Lett.) 20, 102 (2007)

[7] Q. Feng, B. Tryon, L.J. Carroll, T.M. Pollock, Mater. Sci. Eng. A 458, 184 (2007)

[8] Y. Wu, T. Narita, Surf. Coat. Technol. 202, 140 (2007)

[9] C.T. Liu, J. Ma, X.F. Sun, J. Alloys Compd. 491, 522 (2010)

[10] A. Karabela, L.G. Zhao, J. Tong, N.J. Simms, J.R. Nicholls, M.C. Hardy, Mater. Sci. Eng. A 528, 6194 (2011)

[11] Z.X. Shi, J.R. Li, S.Z. Liu, Trans. Nonferr. Met. Soc. China 22, $534(2012)$

[12] A.M. Huntz, B. Lefevre, F. Cassino, Mater. Sci. Eng. A 290, 190 (2000)

[13] Z.G. Zhang, P.Y. Hou, F. Gesmundo, Y. Niu, Appl. Surf. Sci. 253, 881 (2006)

[14] C. Ostwald, H.J. Grabke, Corros. Sci. 46, 1113 (2004)

[15] C. Liu, K.W. Li, J. Shen, J. Zhang, L.H. Lou, Metall. Mater. Trans. A 43A, 405 (2012)

[16] N. Birks, G.H. Meier, F.S. Pettit, Introduction to the Hightemperature Oxidation of Metals (Cambridge University Press, New York, 2006)

[17] C.S. Giggins, B.H. Kear, F.S. Pettit, J.K. Tien, Metall. Mater. Trans. B 5, 1685 (1974)

[18] Z.M. Li, S.Q. Qian, W. Wang, Appl. Surf. Sci. 257, 10414 (2011)

[19] L. Wang, X.G. Liu, J. Zhang, L.H. Lou, J. Iron Steel Res. 23, 353 (2011)

[20] J.A. Nychka, D.R. Clarke, G.H. Meier, Mater. Sci. Eng. A 490, 359 (2008)

[21] J. Chao, J.L. Gonzalez-Carrasco, Mater. Sci. Eng. A 230, 39 (1997) 